\title{
Extensive white matter abnormalities in patients with first-episode schizophrenia: A diffusion tensor imaging (DTI) study
}

\section{Citation}

Lee, Sang-Hyuk, Marek Kubicki, Takeshi Asami, Larry J. Seidman, Jill M. Goldstein, Raquelle I. Mesholam-Gately, Robert W. McCarley, and Martha E. Shenton. 2013. Extensive White Matter Abnormalities in Patients with First-Episode Schizophrenia: A Diffusion Tensor Imaging (DTI) Study. Schizophrenia Research 143, no. 2-3: 231-238. doi:10.1016/j.schres.2012.11.029.

\section{Published Version}

doi:10.1016/j.schres.2012.11.029

\section{Permanent link}

http://nrs.harvard.edu/urn-3:HUL.InstRepos:28548725

\section{Terms of Use}

This article was downloaded from Harvard University's DASH repository, and is made available under the terms and conditions applicable to Other Posted Material, as set forth at http:// nrs.harvard.edu/urn-3:HUL.InstRepos:dash.current.terms-of-use\#LAA

\section{Share Your Story}

The Harvard community has made this article openly available.

Please share how this access benefits you. Submit a story.

\section{Accessibility}




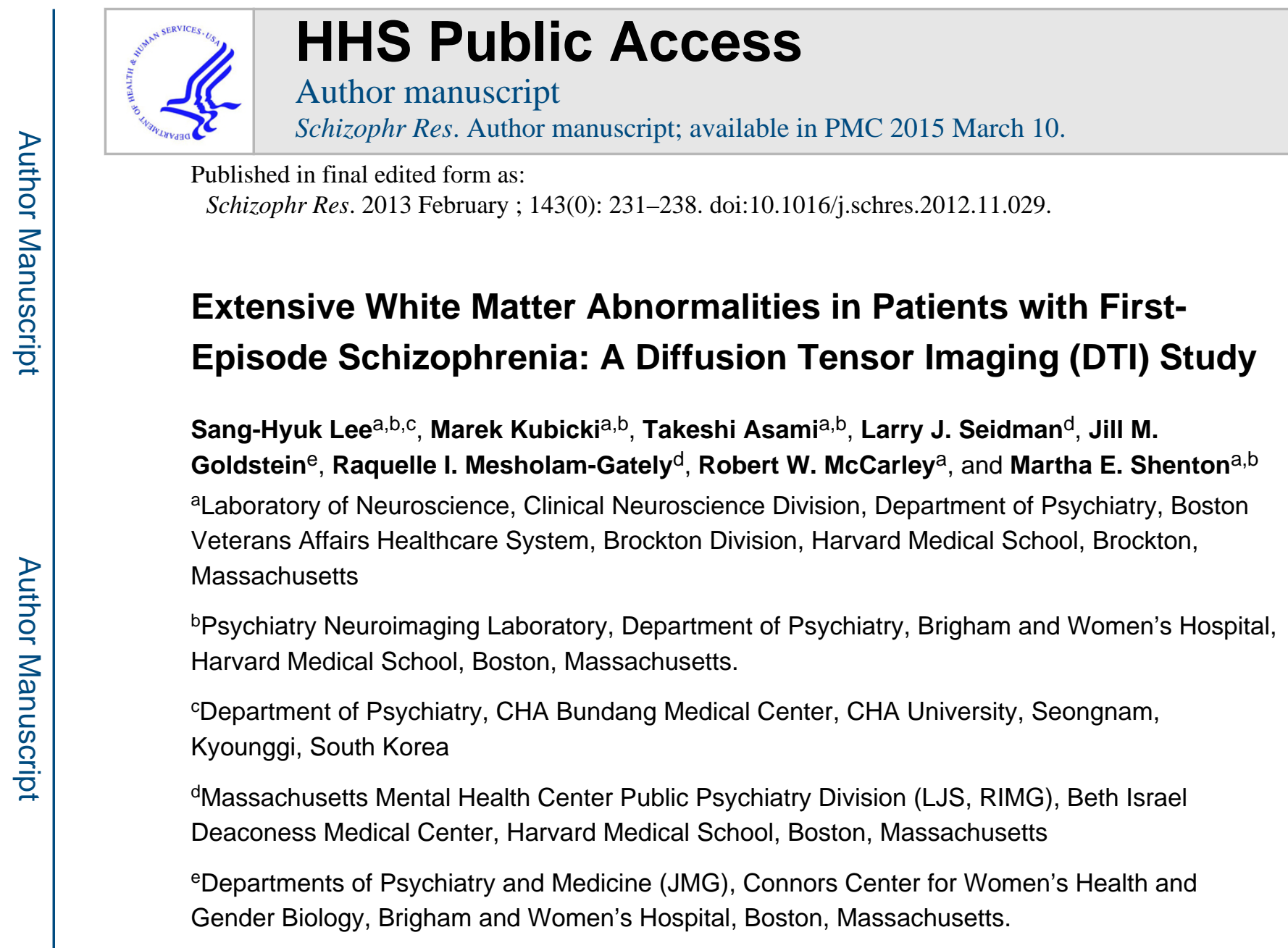

\begin{abstract}
Background-Previous voxelwise Diffusion Tensor Imaging (DTI) investigations of white matter in first-episode schizophrenia (FESZ) have been limited to the analysis of Fractional Anisotropy (FA) and mean diffusivity (MD), with their findings inconsistent in terms of the anatomical locations and extent of abnormalities. This study examines white matter abnormalities in FESZ, compared with healthy controls, using a tract-based spatial statistics (TBSS) approach applied to multiple measures of tract integrity, and correlates these findings with symptom severity.
\end{abstract}

\footnotetext{
(C) 2012 Elsevier B.V. All rights reserved.

Address correspondence to Sang-Hyuk Lee, Department of Psychiatry, CHA Bundang Medical Center, CHA University School of Medicine, 59 Yatapro, Bundang, Seongnam Kyounggi, 463-712 South Korea; leesanghyuk@yahoo.com.

The authors report no biomedical financial interests or potential conflicts of interest

Contributors Sang-Hyuk Lee, Marek Kubicki, Takeshi Asami and Martha E. Shenton designed the study and wrote the protocol. Sang-Hyuk Lee also wrote the first draft of the manuscript. Larry J. Seidman, Raquelle I. Mesholam-Gately, Jill M. Goldstein, Robert W. McCarley and Martha E. Shenton managed the recruitment and collected clinical information of participants. Martha E. Shenton supervised the statistical analyses and edited multiple iterations of the manuscript. All authors contributed to and have improved the final manuscript.

Publisher's Disclaimer: This is a PDF file of an unedited manuscript that has been accepted for publication. As a service to our customers we are providing this early version of the manuscript. The manuscript will undergo copyediting, typesetting, and review of the resulting proof before it is published in its final citable form. Please note that during the production process errors may be discovered which could affect the content, and all legal disclaimers that apply to the journal pertain.
} 
Methods-Seventeen first-episode patients with schizophrenia and seventeen age- and gendermatched healthy controls (HC) participated in this imaging study where FA, MD, and axial and radial diffusivity were compared between the two groups using TBSS.

Results-First-episode patients with schizophrenia showed lower FA values in the genu and body of corpus callosum, the internal capsule, the external capsule, the fornix, the superior, inferior fronto-occipital fasciculus, the cingulum, and the uncinate fasciculus compared with HC. Increased MD and radial diffusivity were shown in virtually all white matter regions. There was no significant difference, however, observed for axial diffusivity between the two groups. Pearson correlation analysis showed that the FA values of the right inferior fronto-occipital fasciculus were positively correlated with positive symptoms, negative symptoms, and total correct items of the Wisconsin Card Sorting Test. FA values of right external capsule also showed significant positive correlation with category completed scores of the WCST.

Conclusions-These data suggest extensive, possibly myelin related white matter disruptions in FESZ.

\section{Keywords}

first-episode schizophrenia; diffusion tensor imaging; fractional anisotropy; TBSS; radial diffusivity; myelin

\section{Introduction}

Previous functional and structural studies have suggested a loss of normal connectivity in schizophrenia (McGuire and Frith, 1996; Weinberger et al., 1992; Wernicke, 1906). White matter lesions could be the basis of this disconnectivity in schizophrenia (see review in Shenton et al.[2001]). Postmortem and genetic studies further suggest that schizophrenia might be related to myelin abnormalities (Davis et al., 2003; Uranova et al., 2001; Uranova et al., 2004), although axonal abnormalities might be involved as well (Mendelsohn et al., 2006).

Diffusion tensor imaging (DTI) techniques make it possible to investigate micro-structural white matter abnormalities in vivo. With this technique, Fractional Anisotropy (FA), a deviation from isotropic diffusion of water molecules, as well as mean diffusivity (MD), a scalar measure of the total diffusion within a voxel, can be measured (Basser and Jones, 2002). Previous DTI studies in first-episode schizophrenia (FESZ) and chronic schizophrenia report FA reductions, along with increased MD in various white matter tracts and regions (Kubicki et al., 2007; Kyriakopoulos and Frangou, 2009). These abnormalities could support 'the disconnectivity hypothesis' in schizophrenia.

Studies of FESZ are particularly important, since this population of patients is much less confounded by medication, effects of aging, and long-term substance abuse, as well as longterm effects of having a chronic illness. In addition, if white matter abnormalities are reported consistently at the onset of schizophrenia, such reports might suggest information relevant to the neurodevelopmental origin of schizophrenia. However, if white matter abnormalities are not present in FESZ, or are less extensive than in chronic schizophrenia, white matter abnormalities might be more related to late development or degeneration. 
DTI findings of FESZ thus far, however, remain inconsistent and therefore inconclusive. While several studies have shown no differences between FESZ patients and HC (Friedman et al., 2008; Price et al., 2005; Price et al., 2008; White et al., 2009), other studies have shown evidence for widespread white matter abnormalities (Cheung et al., 2008; Federspiel et al., 2006; Hao et al., 2006; Price et al., 2007). Further, only a few studies report no FA abnormalities but these studies were able to identify group differences in other diffusion indices such as geometric indices partitioning the diffusion into linear, planar and spherical diffusion measures, and displacement values using high $b$-value $\left(b>3000 \mathrm{~s} / \mathrm{mm}^{2}\right)$ diffusionweighted imaging methods, which provide a fuller account of white matter integrity and more specific axonal pathology (Chan et al., 2010; Mendelsohn et al., 2006). There is thus a need to investigate further DTI findings in FESZ.

To examine the anatomical location of DTI abnormalities in FESZ, voxel-based analysis (VBA) has advantages over a region of interest (ROI) approach. ROI methods are limited to localized white matter regions or tracts, whereas VBA is able to analyze the whole brain at once. VBA has shown, in fact, the most positive findings in FESZ (Federspiel et al., 2006; Hao et al., 2006). These findings, however, remain inconsistent when it comes to specific tracts (reported locations usually do not overlap) and the extent of white matter abnormalities.

Moreover, most VBA studies in FESZ are limited to an analysis of FA and MD. FA and MD may not be sufficient for investigating specific axonal or myelin abnormalities. In mouse DTI studies, axonal damage without myelin damage has been associated with a decrease in axial diffusivity (Sun et al., 2006), whereas demyelination has been associated with an increase in radial diffusivity without changes in axial diffusivity (Song et al., 2005). An investigation of these measures could serve to inform the nature of white matter pathology in schizophrenia (Seal et al., 2008; Smith et al., 2006; Smith et al., 2007).

Tract-Based Spatial Statics (TBSS, version 1.2) (Smith et al., 2006; Smith and Nichols, 2009) is believed to reduce some of the methodological problems of previous VBA approaches that were associated with misalignment and smoothing problems. TBSS also takes into account non-normal distributions of FA in certain brain regions (Smith et al., 2007). Accordingly, because of the range of functions that TBSS is capable of performing, we investigated white matter abnormalities in FESZ using TBSS. Additionally, we combined TBSS skeleton with white matter atlases (Mori et al., 2005), a method that makes possible ROI analyses as a way to confirm TBSS results (Karlsgodt et al., 2009).

\section{Methods and Materials}

\section{Subjects}

Seventeen patients with FESZ were recruited by referrals from clinicians at Beth Israel Deaconess Medical Center-Massachusetts Mental Health Center and Children's Hospital, Harvard Medical School, Massachusetts. Seventeen healthy controls (HC) were recruited through newspaper advertisements and advertisements on the websites (www.bostoncidar.org and www.schizophrenia.com). All subjects were part of Boston CIDAR (the Center for Intervention Development and Applied Research) study. DSM-IV 
diagnoses were based on interviews with the Structured Clinical Interview for DSM-IV-TR (SCID), Research Version (First et al., 2002a) and information from patient medical records. $\mathrm{HC}$ were group matched to FESZ for age, gender and parental socioeconomic status (PSES). Using the Structured Clinical Interview for DSM-IV-TR, Non-patient Edition (First et al., 2002b), HCs were excluded if: 1) they currently met the criteria for any psychosis, major depressive disorder, dysthymic disorder, bipolar disorder, obsessive compulsive disorder, post traumatic stress disorder, dissociative disorders, anorexia nervosa, bulimia nervosa, or developmental disorders, 2) they had a history of any psychosis, major depression (recurrent), bipolar disorder, obsessive compulsive disorder, post traumatic stress disorder, developmental disorders, or psychiatric hospitalization, 3) they had current or past use of antipsychotics for any psychiatric condition (other past psychotropic medication use acceptable, but must have been off medicine for at least 6 months before participating in the study, except for prn medications like sleeping medications or anxiolytic agents, like betablockers for performance anxiety, tremors, etc.), 4) they had any history of electroconvulsive therapy, 5) there was evidence of any prodromal symptoms, or schizotypal or other Cluster A personality disorders, or 6) they reported having a first-degree relative with psychosis.

Exclusion criteria for all subjects were: sensory-motor handicaps, neurological disorders, medical illnesses that significantly impair neurocognitive function, diagnosis of mental retardation, education less than $5^{\text {th }}$ grade if under 18 or less than $9^{\text {th }}$ grade if 18 or above, not fluent in English, DSM-IV substance abuse in the past month, DSM-IV substance dependence, excluding nicotine, in the past 3 months, current suicidality, no history of ECT within the past five years for patients and no history of ECT ever for controls, or study participation by another family member.

Thirteen patients were receiving antipsychotic medication at the time of testing. Medication dose equivalent to chloropromazine at the time of the scan was $393.3 \mathrm{mg}(\mathrm{SD}=358.2)$ (Woods, 2003). Premorbid intellectual abilities were estimated using the reading subtest from the Wide Range Achievements Test-4 (WRAT-4) (Wilkinson and Robertson, 2006), and current intellect was estimated with two subtests from the Wechsler abbreviated Scale of Intelligence (WASI) (32). Socioeconomic status (SES) of schizophrenia and HCs, and those of their parents (PSES), were evaluated using the Hollingshead (1965) (33) two-factor index. Clinical symptoms were measured using The Brief Psychiatric Rating Scale (BPRS) (34). The 64-card computerized version of the Wisconsin Card Sorting Test (WCST) (35) was also administered by trained neuropsychological testers under the supervision of a psychologist. All patients were scanned at Brigham and Women's Hospital. The study was approved by the local IRB committees at Harvard Medical School, Beth Israel Deaconess Hospital, Brigham and Women's Hospital, and at the Veteran Affairs Boston Healthcare System, Brockton campus, and all study participants gave written informed consent prior to study participation.

\section{MRI acquisition}

Diffusion data were acquired on a 3 Tesla GE Echospeed system (General Electric Medical Systems, Milwaukee, WI). Diffusion-weighted images were acquired using an echo planar 
imaging sequence, with the following parameters: TR $17000 \mathrm{~ms}$, TE $78 \mathrm{~ms}$, FOV $24 \mathrm{~cm}$, 144×144 matrix, $1.7 \mathrm{~mm}$ slice thickness. A double echo option was used to reduce eddycurrent related distortions. To reduce impact of EPI spatial distortions, an 8 Channel coil and ASSET (Array Spatial Sensitivity Encoding techniques, GE) with a SENSE-factor (speedup) of 2 was used. Eighty-five axial slices parallel to the AC-PC line covering whole brain were acquired in 51 directions with $b=900 \mathrm{~s} / \mathrm{mm} 2$. Eight baseline scans with $b=0 \mathrm{~s} / \mathrm{mm} 2$ were also acquired. Diffusion-Tensor Images (DTIs) were estimated from the Diffusion-Weighted Images using Least-Squares method.

\section{Tract-based spatial statistics}

For voxelwise statistical analysis, Tract-Based Spatial Statistics (TBSS) version 1.2 was used. Diffusion tensor images (FA, trace, axial and radial diffusivity) were pre-processed using the FMRIB Software Library (FSL, Oxford), including skull stripping and eddy current correction Briefly, FA maps were first created for each subject using FSL. Then, FA maps were aligned into a common (Montreal Neurologic Institute 152 standard) space using the nonlinear registration tool FNIRT. All transformed FA images were averaged to create a mean FA image, and the tracts were narrowed to generate a mean FA skeleton, where centers of white matter tracts common to all the subjects were created. Voxel values of each subject's FA map were projected onto the skeleton. The FA threshold was then set at 0.2 (TBSS default), in order to confine the analysis to white matter. Voxelwise permutationbased nonparametric inference (Nichols and Holmes, 2002) was performed on skeletonised FA data, using FSL Randomize version 2.1. Both HC > FESZ and FESZ > HC contrasts were tested, with 5000 permutations and the significance level was set at $p<0.05$, corrected for family-wise error rate. We also performed a multiple comparisons correction using threshold-free cluster enhancement (TFCE) (Smith and Nichols, 2009), which allowed us to avoid making an arbitrary choice of the cluster-forming threshold, while preserving the sensitivity benefits of clusterwise correction.

To compare trace, axial diffusivity and radial diffusivity, we used FSL using the FA images to achieve nonlinear registration and skeletonisation stages, and also to estimate the projection vectors from each individual subject onto the mean FA skeleton. The nonlinear warps and skeleton projection can then also be applied to other images

\section{Comparison of the skeleton FA values, atlas-based segmentation and correlation analysis}

3D individual FA skeletons were extracted from all 4D skeletonised images. The FA skeleton was manually separated into two regions (cerebrum and non-cerebrum [brainstem and cerebellum]) and then, mean FAs of whole brain FA skeleton, as well as its components were calculated using 3D-slicer (v2.8, http://www.slicer.org). For atlas-based segmentation and correlational analysis, all extracted skeletons were overlaid with the John Hopkins University (JHU) DTI-based probablistic tractography atlas, which contains 50 white matter tracts/regions (Hua et al., 2008; Mori et al., 2005; Wakana et al., 2007). Averaged DTI indices were then calculated for each atlas region. In some regions where the skeleton and JHU tract differed, the regions of JHU tracts were edited by one of the researchers (J.A.), blind to the diagnosis, in order to incorporate contiguous and inclusive sections of the skeleton. 


\section{Statistical Analysis}

To compare the demographic findings between FESZs and HCs, independent $t$ tests and Fisher's exact tests were used. To determine group differences in mean FA of the global FA skeleton, we conducted statistical analyses, as follows. First, repeated measure ANOVA was used to compare the skeleton FA values in whole brain with group as a between-subjects factor, and regions (cerebrum, non-cerebrum [brain stem and cerebellum]), as the withinsubjects factor. Second, independent sample t-tests were applied with cutoff $p$ values set at 0.05 (for whole brain FA skeleton comparison) and 0.025 (0.05/2 components, for cerebrum and non-cerebrum). Third, TBSS was applied to find white matter abnormalities of the specific tracts and regions. For correlational analysis, Pearson correlations were used to investigate the relationship between the severity of each BPRS scores, executive functioning, and measures of white matter integrity.

\section{Results}

\section{Demographic characteristics for first-episode schizophrenia and healthy controls}

There were no statistically significant differences between FESZs and HCs in demographic characteristics (Table 1). All subjects were right-handed. In patients with schizophrenia, mean age of onset was $20.3(\mathrm{SD}=4.6)$ years and mean duration of illness was $10.9(\mathrm{SD}=7.4)$ months. In medicated patients with schizophrenia $(\mathrm{N}=12)$, medication dose equivalent to chloropromazine at the time of the scan was $393.3(\mathrm{SD}=358.2) \mathrm{mg}$; and medication duration at scan was $4.56(\mathrm{SD}=3.10)$ months. Five patients were medication-free at the time of scanning. Total BPRS score for the patients was: 41.9 ( $\mathrm{SD}=12.6)$; Positive symptom (Thinking disturbance BPRS factor) score: 6.4 ( $\mathrm{SD}=2.8$ ); Negative symptom (WithdrawalRetardation BPRS factor) score: $6.0(\mathrm{SD}=2.9)$

\section{Whole brain skeleton analyses}

3D individual whole brain FA skeletons, extracted from 4D all skeletonised images in the process of TBSS, were manually segmented by the researcher (J.A.), blind to the diagnosis, into two brain regions (cerebrum, non-cerebrum [brain stem and cerebellum]). Mean FA values for each of the brain regions were then analyzed.

Repeated measures ANOVA revealed a group effect for whole brain mean FA values $\left(\mathrm{F}_{31,2}=5.8, \mathrm{p}=0.021\right)$. There was also a significant group by region interaction $\left(\mathrm{F}_{31,2}=6.2\right.$, $\mathrm{p}=0.018$ ). Independent $\mathrm{t}$-tests showed that the patient group had significantly smaller mean FAs for whole brain FA skeleton compared with HCs (mean FA \pm SD; schizophrenia: $0.436 \pm 0.015$, HC: $0.449 \pm 0.016, \mathrm{t}_{32}=-2.43, \mathrm{p}=0.021$ ). Subsequent independent $\mathrm{t}$-tests, showed significantly lower mean FA values for cerebral white matter $\left(\mathrm{t}_{32}=-2.46, \mathrm{p}=0.019\right.$, cutoff $=0.025$ ), but no group differences in mean FA values for non-cerebral skeleton $\left(\mathrm{t}_{32}=-1.77, \mathrm{p}=0.09\right)$.

\section{Fractional Anisotropy}

FA values in cerebrum were measured by TBSS and by atlas-based segmentation method. 
TBSS showed extensive FA reduction in the white matter in FESZ (Figure 1). FESZ showed lower FA values in the genu and body of corpus callosum, the internal capsule, the external capsule, the fornix, the superior, inferior fronto-occipital fasciculus, the cingulum, and the uncinate fasciculus compared with HCs. When we used an ANCOVA design, where we used chloropromazine equilvalent as a nuisance covariate (Since there is no control subjects taking antipsychotic medication, their mean CPZ equivalent dose was all 0 and demeaned values also 0) (Grimm et al., 2009), the region of FA reduction remained the same. Also, comparing schizophrenia subjects exposed to antipsychotic drugs to non-medicated schizophrenia did not reveal significant different FA values of regions.

Supplementary atlas-based segmentation supported TBSS results by also showing extensive FA reductions in the white matter of FESZ. That is, patients with FESZ showed significantly lower FA values in the genu and splenium of corpus callosum, the internal capsule, the fornix, right superior frontooccipital fasciculus, left inferior frontooccipital fasciculus, cingulum, and uncinate fasciculus compared with HCs using atlas-based segmentation (Table 2). Atlas-based segmentation also showed FA reductions of trend-level significance in the body of corpus callosum ( $\mathrm{t}=-1.97, \mathrm{df}=32, \mathrm{p}=0.057)$ and the right external capsule $(\mathrm{t}=-1.79, \mathrm{df}=32, \mathrm{p}=0.083)$ of FESZ compared with HCs.

\section{Non-FA (Trace, Axial diffusivity and Radial diffusivity)}

Non-FA values were also measured by TBSS and atlas-based segmentation method. TBSS showed that trace and radial diffusivity in schizophrenia patients were higher in almost all the white matter regions than in HCs (Figure 2, 3). Supplementary atlas-based segmentation again supported TBSS results by showing the same results. In terms of axial diffusivity, there was no significant difference between FESZ and HCs.

\section{Exploratory correlation analysis in patients with schizophrenia}

Pearson correlation analysis $(n=15)$ showed that FA values of the right inferior frontooccipital fasciculus were positively correlated with the BPRS total scores ( $\mathrm{r}=0.601$, $\mathrm{p}=0.018)$, positive symptom scores $(\mathrm{r}=0.568, \mathrm{p}=0.027)$ and negative symptom scores $(\mathrm{r}=0.564, \mathrm{p}=0.029)$.

In terms of executive function, Pearson correlation analysis also showed that FA values of the right inferior fronto-occipital fasciculus were positively correlated with the scores of category completed $(\mathrm{r}=0.673, \mathrm{p}=0.012)$ in the WCST, and negatively correlated with scores of total error $(r=-0.605, p=0.029)$ in the WCST. FA values of right external capsule also showed a statistically significant positive correlation with category completed scores of the WCST $(r=0.715, p=0.006)$, and significant negative correlation with perserverative responses $(\mathrm{r}=-0.577, \mathrm{p}=0.039)$.

Also, FA values of left cingulum (hippocampus) showed statistically significant positive correlations with the WRAT-4 word reading scores $(\mathrm{r}=0.547, \mathrm{p}=0.035)$ and WRAT-4 total reading scores $(\mathrm{r}=0.562, \mathrm{p}=0.023)$. And FA values of right fornix / Stria terminalis were significantly correlated with WRAT-4 total reading scores $(\mathrm{r}=0.504 \mathrm{p}=0.047)$. 
Medication related variables and duration of illness were not significantly correlated with mean FAs of the skeletons in whole brain, cerebrum, and white matter tracts.

\section{Discussion}

This is the first report to suggest extensive white matter myelin disruptions in FESZ using new voxel-based diffusion tensor imaging, i.e., TBSS.

At the whole brain and cerebral level, FESZ showed significantly lower mean FA for whole brain and for the cerebral FA skeleton. At the tract level, both TBSS and the atlas-based segmentation method results showed extensive abnormalities for most white matter tracts in FESZ, including the corpus callosum, the fronto-occipital fasciculus, frontal, temporal, parietal, occipital and subcortical regions. Our results thus demonstrate that extensive brain regions are disrupted in the early stages of schizophrenia. These results are consistent with Hao et al. (Hao et al., 2006) who, using a statistical parameters maps method, rather than TBSS, and focusing only on mean FA differences, also reported wide-spread white matter abnormalities in FESZ.

Based on our results, we suggest that extensive white matter pathology is already extant in FESZ. Although anatomical location of DTI abnormalities in FESZ can vary considerably among studies, the most frequently and consistently identified white matter tracts are the corpus callosum (Federspiel et al., 2006; Price et al., 2007) and the fronto-occipital fasciculus (Federspiel et al., 2006; Szeszko et al., 2008). The other identified regions are broadly defined as temporal (Federspiel et al., 2006; Hao et al., 2006), parietal (Hao et al., 2006; Peters et al., 2009) and frontal (Hao et al., 2006; Peters et al., 2009) regions in FESZ. Taken together, these wide spread abnormalities observed in previous studies are consistent with our findings of extensive white matter abnormalities in FESZ.

We should, nonetheless, note the differences in methodological approaches between the current study and other published studies. By virtue of high field strength (3T), and multiple B0 images that were collected and averaged, signal to noise ratio in this study is higher than in previous schizophrenia studies, especially those using $1.5 \mathrm{~T}$ data. This allows for more precise between subject registration, and thus improves the detection of brain abnormalities. Moreover, TBSS is generally more sensitive to changes in white matter regions than are other voxel-based morphometry methods (Focke et al., 2008), which might be one of the reasons for finding relatively more extensive abnormalities than have been reported in the other studies of white matter tract abnormalities in FESZ. Thirdly, antipsychotic medications may decrease mean FA values in FESZ as a result of altered white matter function in FESZ brains. It has been suggested that some antipsychotics can result in the release of inflammatory cytokines and free radicals from activated microglia, both of which have been known to result in white matter alterations (Monji et al., 2009). Having that in mind, we applied ANCOVA, considering medication as a covariate, but found that the results were almost identical to those that did not take medication into account.

We thus reported a reduction of FA, similar to previous studies, but we also reported no change in axial diffusivity, but increases in trace and in radial diffusivity in extensive 
regions of FESZ, which, taken together, suggest myelin involvement in white matter FESZ pathology. These findings are consistent with neuropathological investigations in schizophrenia, which have identified reductions in the size and density of interfascicular oligodendrocytes and a reduced level of myelin basic protein (MBP) in white matter in schizophrenia (Tkachev et al., 2007). These results are also consistent with the oligodendrocyte abnormalities described in postmortem schizophrenia studies (Flynn et al., 2003; Uranova et al., 2001; Uranova et al., 2004), genetic studies reporting abnormalities in genes related to oligodendrocytes and white matter development (Davis et al., 2003; Segal et al., 2007), and studies showing similarities between schizophrenia and neurologic demyelinating diseases such as metachromatic leukodystrophy, which affect frontal white matter and produce symptoms very similar to schizophrenia (Black et al., 2003). However, since such findings have not been reported for FESZ, our results suggest that myelin abnormalities may contribute to the pathophysiologies observed in the early stages of schizophrenia.

More specifically, neurodevelopmental theories have suggested demyelination during adolescence and adulthood (Ashtari et al., 2007; Hyde et al., 1992), and an arrest in the normal process of myelination during brain development in adolescence (Bartzokis, 2002). Benes also found the abnormalities of myelination in the frontal cortex and hippocampus in schizophrenia (Benes, 1989). Our findings of myelin disruption in FESZ support these theories.

Correlations between several white matter tracts and positive and negative symptoms are of particular interest, as several studies suggest a paradoxical, positive correlation between severity of positive symptoms and FA. Pearson correlation analysis $(n=15)$ in our study showed that FA values of the right inferior fronto-occipital fasciculus are positively correlated with the BPRS total scores, positive symptom scores and negative symptom scores in FESZ. FA of this tract showed trend-level significance for correlation with the hallucination score of BPRS ( $r=0.496, p=0.060)$. Since the inferior fronto-occipital fasciculus connects frontal cortex with temporal cortex (Catani et al., 2002), there is the possibility that the inferior fronto-occipital fasciculus could be related to positive symptoms such as hallucinations and negative symptoms. Previous studies (Hubl et al., 2004; Mulert et al., 2012; Seok et al., 2007; Shergill et al., 2007) showing that positive symptoms like auditory hallucinations were positively correlated with FA in the anterior corpus callosum, cingulum and superior longitudinal fasciculus support this positive correlation. As those studies suggest, relatively high FA within these frontotemporal tracts could reflect greater connectivity between the frontal and temporal cortex, which might perturb normal communication between areas involved in the generation and monitoring of inner speech (Shergill et al., 2007). The inferior fronto-occipital fasciculus in FESZ may also paradoxically perturb normal communication between areas involved in the generation and monitoring of inner speech.

An early study reported the negative correlations between inferior frontal white matter and negative symptoms (Wolkin et al., 2003), However, other reports (Shin et al., 2006; Skelly et al., 2008) have shown that negative symptoms are also positively correlated with FA values in close proximity to the insula cortex, which is consistent with our positive 
correlation between mean FA values in the inferior fronto-occipital fasciculus and negative symptoms. Since the inferior fronto-occipital fasciculus might be involved in insula connectivity, and both the inferior fronto-occipital fasciculus and the insula are known to play a role in emotional regulation and cognition, dysfunction of those regions could result in negative symptoms (Catani et al., 2002).

In terms of the relationship between white matter tracts and executive functions, the right inferior fronto-occipital fasciculus showed positive correlations with the scores of category completed, total correct and conceptual level responses in the WCST and negatively correlated with the scores of total error, and preseverative error in the WCST. Since the inferior fronto-occipital fasciculus is also related to higher cognitive functioning, low FA value of the inferior fronto-occipital fasciculus may result in disinhibition, poor decisionmaking, and an inability to follow the rules (Catani et al., 2002), which are the central obstacles to performing the WCST. Significant correlations between mean FA values of the right external capsule and some items of the WCST are harder to interpret. There is no information about this relationship in the literature. However, since the inferior frontooccipital fasciculus passes through the anterior floor of external capsule, their function as well as involvement in the cognitive symptoms in schizophrenia could be similar. A report of the presence of hyperintense lesions within the internal/external capsule that were negatively correlated with executive functions in older healthy people (O'Brien et al., 2002) also supports this finding.

Of note, paradoxical correlations between positive and negative symptoms and the values of FA in this study have been suggested by several authors to be a consequence of the loss of crossing fibers (Hoptman et al., 2008; Kim et al., 2012). We believe, however, that this possibility is less likely since the significant correlations with WCST performance are in the expected direction.

The small number of regions demonstrating significant clinical and cognitive correlations in patients with FESZ is especially surprising given the extensive white matter abnormalities. It is also in contrast with chronic schizophrenia studies, which usually show extensive associations between negative symptoms and white matter abnormalities (Sanfilipo et al., 2000; Wible et al., 2001). It is, however, consistent with results of other imaging studies, and suggests that the severities of clinical symptoms or abnormalities of specific fiber tracts in FESZ are not yet prominent enough to show significant correlations.

This study has several limitations. First, we scanned, to date, only 17 patients with a first episode of schizophrenia and 17 matched healthy controls. Future studies with a larger number of patients are needed to confirm our findings. Second, because our correlation analysis between FAs of white matter and BPRS, WCST were exploratory in nature, a confirmation of these findings will be necessary in future planned studies.

In conclusion, our findings suggest extensive white matter abnormalities in FESZ, which are most likely related to disruptions in myelin integrity. 


\section{Acknowledgments}

Role of funding source The funding source had no role in study design; the collection, analysis nor interpretation of data; writing of the paper; nor in the decision for publication.

This study was supported, in part, by grants from P50 MH 080272 (RWM, MES, LJS, JMG, RMG), RO1 MH 50747 (MES), R01 MH 40799 (RWM), VA MERITs (JJL, MES, RWM), and the Commonwealth Research Center of the Massachusetts Department of Mental Health, SCDMH82101008006 (LJS, RMG). This study was also supported by Clinical Translational Science Award UL1RR025758 and General Clinical Research Center Grant M01RR01032 to Harvard University and hospital facilities at Beth Israel Deaconess, Brigham and Women's Hospital, and Massachusetts General Hospital from the National Center for Research Resources. The content is solely the responsibility of the authors and does not necessarily represent the official views of the National Center for Research Resources or the National Institutes of Health. We thank Psychiatry Neuroimaging Laboratory Software Engineer, Ryan Eckbo, M.Sc., Research Assistants, including Padmapriya Srinivasan, M.S., Jorge L. Alvarado, B.S., Kathryn Hawley, B.A., Mai-Anh Vu, B.A., Thomas Ballinger, B.A., Tali Swisher, B.A. and Paula Pelavin, B.A., Rebecca King, B.S. for their help and support. We also thank the clinical and data management staff from the Boston CIDAR study, including: Joanne Wojcik, Ph.D, APRN, Ann Cousins, Ph.D., APRN, Michelle Friedman-Yakoobian, Ph.D., Kristen Woodberry, Ph.D., Corin Pilo, LMHC, Andréa Gnong Granato, MSW, Lauren Gibson, Ed.M., Sarah Hornbach, B.A., Julia Schutt, B.A., Kristy Klein, Ph.D., Maria Hiraldo, Ph.D., Grace Francis, Ph.D., Rachael Serur, B.S., Grace Min, Ed.M., Alison Thomas, B.A., and Molly Franz, B.A..

\section{References}

Ashtari M, Cottone J, Ardekani BA, Cervellione K, Szeszko PR, Wu J, et al. Disruption of white matter integrity in the inferior longitudinal fasciculus in adolescents with schizophrenia as revealed by fiber tractography. Arch Gen Psychiatry. 2007; 64(11):1270-1280. [PubMed: 17984396]

Bartzokis G. Schizophrenia: breakdown in the well-regulated lifelong process of brain development and maturation. Neuropsychopharmacology. 2002; 27(4):672-683. [PubMed: 12377404]

Basser PJ, Jones DK. Diffusion-tensor MRI: theory, experimental design and data analysis - a technical review. NMR Biomed. 2002; 15(7-8):456-467. [PubMed: 12489095]

Benes FM. Myelination of cortical-hippocampal relays during late adolescence. Schizophr Bull. 1989; 15(4):585-593. [PubMed: 2623440]

Black DN, Taber KH, Hurley RA. Metachromatic leukodystrophy: a model for the study of psychosis. J Neuropsychiatry Clin Neurosci. 2003; 15(3):289-293. [PubMed: 12928504]

Catani M, Howard RJ, Pajevic S, Jones DK. Virtual in vivo interactive dissection of white matter fasciculi in the human brain. Neuroimage. 2002; 17(1):77-94. [PubMed: 12482069]

Chan WY, Yang GL, Chia MY, Lau IY, Sitoh YY, Nowinski WL, et al. White matter abnormalities in first-episode schizophrenia: a combined structural MRI and DTI study. Schizophrenia research. 2010; 119(1-3):52-60. [PubMed: 20056394]

Cheung V, Cheung C, McAlonan GM, Deng Y, Wong JG, Yip L, et al. A diffusion tensor imaging study of structural dysconnectivity in never-medicated, first-episode schizophrenia. Psychol Med. 2008; 38(6):877-885. [PubMed: 17949516]

Davis KL, Stewart DG, Friedman JI, Buchsbaum M, Harvey PD, Hof PR, et al. White matter changes in schizophrenia: evidence for myelin-related dysfunction. Arch Gen Psychiatry. 2003; 60(5):443456. [PubMed: 12742865]

Federspiel A, Begre S, Kiefer C, Schroth G, Strik WK, Dierks T. Alterations of white matter connectivity in first episode schizophrenia. Neurobiol Dis. 2006; 22(3):702-709. [PubMed: 16624566]

First, MB.; Spitzer, RL.; Gibbon, M.; Williams, JBW. Structured Clinical Interview for DSM-IV-TR Axis I Disorders, Research Version. Biometrics Research, New York State Psychiatric Institute; New York: 2002a.

First, MB.; Spitzer, RL.; Miriam, G.; Williams, JBW. Structured Clinical Interview for DSM-IV-TR Axis I Disorders, Research Version, Non-patient Edition. (SCID-I/NP). Biometrics Research, New York State Psychiatric Institute; New York: 2002b.

Flynn SW, Lang DJ, Mackay AL, Goghari V, Vavasour IM, Whittall KP, et al. Abnormalities of myelination in schizophrenia detected in vivo with MRI, and post-mortem with analysis of oligodendrocyte proteins. Mol Psychiatry. 2003; 8(9):811-820. [PubMed: 12931208] 
Focke NK, Yogarajah M, Bonelli SB, Bartlett PA, Symms MR, Duncan JS. Voxel-based diffusion tensor imaging in patients with mesial temporal lobe epilepsy and hippocampal sclerosis. Neuroimage. 2008; 40(2):728-737. [PubMed: 18261930]

Friedman JI, Tang C, Carpenter D, Buchsbaum M, Schmeidler J, Flanagan L, et al. Diffusion tensor imaging findings in first-episode and chronic schizophrenia patients. The American journal of psychiatry. 2008; 165(8):1024-1032. [PubMed: 18558643]

Grimm S, Ernst J, Boesiger P, Schuepbach D, Hell D, Boeker H, et al. Increased self-focus in major depressive disorder is related to neural abnormalities in subcortical-cortical midline structures. Human brain mapping. 2009; 30(8):2617-2627. [PubMed: 19117277]

Hao Y, Liu Z, Jiang T, Gong G, Liu H, Tan L, et al. White matter integrity of the whole brain is disrupted in first-episode schizophrenia. Neuroreport. 2006; 17(1):23-26. [PubMed: 16361944]

Hoptman MJ, Nierenberg J, Bertisch HC, Catalano D, Ardekani BA, Branch CA, et al. A DTI study of white matter microstructure in individuals at high genetic risk for schizophrenia. Schizophrenia research. 2008; 106(2-3):115-124. [PubMed: 18804959]

Hua K, Zhang J, Wakana S, Jiang H, Li X, Reich DS, et al. Tract probability maps in stereotaxic spaces: analyses of white matter anatomy and tract-specific quantification. Neuroimage. 2008; 39(1):336-347. [PubMed: 17931890]

Hubl D, Koenig T, Strik W, Federspiel A, Kreis R, Boesch C, et al. Pathways that make voices: white matter changes in auditory hallucinations. Arch Gen Psychiatry. 2004; 61(7):658-668. [PubMed: 15237078]

Hyde TM, Ziegler JC, Weinberger DR. Psychiatric disturbances in metachromatic leukodystrophy. Insights into the neurobiology of psychosis. Arch Neurol. 1992; 49(4):401-406. [PubMed: 1532712]

Karlsgodt KH, Niendam TA, Bearden CE, Cannon TD. White matter integrity and prediction of social and role functioning in subjects at ultra-high risk for psychosis. Biological psychiatry. 2009; 66(6): 562-569. [PubMed: 19423081]

Kim SN, Park JS, Jang JH, Jung WH, Shim G, Park HY, et al. Increased white matter integrity in the corpus callosum in subjects with high genetic loading for schizophrenia. Progress in neuropsychopharmacology \& biological psychiatry. 2012; 37(1):50-55. [PubMed: 22155177]

Kubicki M, McCarley R, Westin CF, Park HJ, Maier S, Kikinis R, et al. A review of diffusion tensor imaging studies in schizophrenia. J Psychiatr Res. 2007; 41(1-2):15-30. [PubMed: 16023676]

Kyriakopoulos M, Frangou S. Recent diffusion tensor imaging findings in early stages of schizophrenia. Curr Opin Psychiatry. 2009; 22(2):168-176. [PubMed: 19553871]

McGuire PK, Frith CD. Disordered functional connectivity in schizophrenia. Psychol Med. 1996; 26(4):663-667. [PubMed: 8817700]

Mendelsohn A, Strous RD, Bleich M, Assaf Y, Hendler T. Regional axonal abnormalities in first episode schizophrenia: preliminary evidence based on high b-value diffusion-weighted imaging. Psychiatry Res. 2006; 146(3):223-229. [PubMed: 16527464]

Monji A, Kato T, Kanba S. Cytokines and schizophrenia: Microglia hypothesis of schizophrenia. Psychiatry Clin Neurosci. 2009; 63(3):257-265. [PubMed: 19579286]

Mori, S.; Wakana, S.; Nagae-Poetscher, LM.; van Zijl, PC. MRI Atlas of Human White Matter. Elsevier; Amsterdam: 2005.

Mulert C, Kirsch V, Whitford TJ, Alvarado J, Pelavin P, McCarley RW, et al. Hearing voices: a role of interhemispheric auditory connectivity? World J Biol Psychiatry. 2012; 13(2):153-158. [PubMed: 21623667]

Nichols TE, Holmes AP. Nonparametric permutation tests for functional neuroimaging: a primer with examples. Human brain mapping. 2002; 15(1):1-25. [PubMed: 11747097]

O’Brien JT, Wiseman R, Burton EJ, Barber B, Wesnes K, Saxby B, et al. Cognitive associations of subcortical white matter lesions in older people. Ann N Y Acad Sci. 2002; 977:436-444. [PubMed: 12480784]

Peters BD, Schmitz N, Dingemans PM, van Amelsvoort TA, Linszen DH, de Haan L, et al. Preliminary evidence for reduced frontal white matter integrity in subjects at ultra-high-risk for psychosis. Schizophrenia research. 2009; 111(1-3):192-193. [PubMed: 19372031] 
Price G, Bagary MS, Cercignani M, Altmann DR, Ron MA. The corpus callosum in first episode schizophrenia: a diffusion tensor imaging study. J Neurol Neurosurg Psychiatry. 2005; 76(4):585587. [PubMed: 15774453]

Price G, Cercignani M, Parker GJ, Altmann DR, Barnes TR, Barker GJ, et al. Abnormal brain connectivity in first-episode psychosis: a diffusion MRI tractography study of the corpus callosum. Neuroimage. 2007; 35(2):458-466. [PubMed: 17275337]

Price G, Cercignani M, Parker GJ, Altmann DR, Barnes TR, Barker GJ, et al. White matter tracts in first-episode psychosis: a DTI tractography study of the uncinate fasciculus. Neuroimage. 2008; 39(3):949-955. [PubMed: 17988894]

Sanfilipo M, Lafargue T, Rusinek H, Arena L, Loneragan C, Lautin A, et al. Volumetric measure of the frontal and temporal lobe regions in schizophrenia: relationship to negative symptoms. Arch Gen Psychiatry. 2000; 57(5):471-480. [PubMed: 10807487]

Seal ML, Yucel M, Fornito A, Wood SJ, Harrison BJ, Walterfang M, et al. Abnormal white matter microstructure in schizophrenia: a voxelwise analysis of axial and radial diffusivity. Schizophrenia research. 2008; 101(1-3):106-110. [PubMed: 18262770]

Segal D, Koschnick JR, Slegers LH, Hof PR. Oligodendrocyte pathophysiology: a new view of schizophrenia. Int J Neuropsychopharmacol. 2007; 10(4):503-511. [PubMed: 17291369]

Seok JH, Park HJ, Chun JW, Lee SK, Cho HS, Kwon JS, et al. White matter abnormalities associated with auditory hallucinations in schizophrenia: a combined study of voxel-based analyses of diffusion tensor imaging and structural magnetic resonance imaging. Psychiatry Res. 2007; 156(2):93-104. [PubMed: 17884391]

Shenton ME, Dickey CC, Frumin M, McCarley RW. A review of MRI findings in schizophrenia. Schizophrenia research. 2001; 49(1-2):1-52. [PubMed: 11343862]

Shergill SS, Kanaan RA, Chitnis XA, O’Daly O, Jones DK, Frangou S, et al. A diffusion tensor imaging study of fasciculi in schizophrenia. The American journal of psychiatry. $2007 ; 164(3)$ : 467-473. [PubMed: 17329472]

Shin YW, Kwon JS, Ha TH, Park HJ, Kim DJ, Hong SB, et al. Increased water diffusivity in the frontal and temporal cortices of schizophrenic patients. Neuroimage. 2006; 30(4):1285-1291. [PubMed: 16406258]

Skelly LR, Calhoun V, Meda SA, Kim J, Mathalon DH, Pearlson GD. Diffusion tensor imaging in schizophrenia: relationship to symptoms. Schizophrenia research. 2008; 98(1-3):157-162. [PubMed: 18031994]

Smith SM, Jenkinson M, Johansen-Berg H, Rueckert D, Nichols TE, Mackay CE, et al. Tract-based spatial statistics: voxelwise analysis of multi-subject diffusion data. Neuroimage. 2006; 31(4): 1487-1505. [PubMed: 16624579]

Smith SM, Johansen-Berg H, Jenkinson M, Rueckert D, Nichols TE, Miller KL, et al. Acquisition and voxelwise analysis of multi-subject diffusion data with tract-based spatial statistics. Nat Protoc. 2007; 2(3):499-503. [PubMed: 17406613]

Smith SM, Nichols TE. Threshold-free cluster enhancement: addressing problems of smoothing, threshold dependence and localisation in cluster inference. Neuroimage. 2009; 44(1):83-98. [PubMed: 18501637]

Song SK, Yoshino J, Le TQ, Lin SJ, Sun SW, Cross AH, et al. Demyelination increases radial diffusivity in corpus callosum of mouse brain. Neuroimage. 2005; 26(1):132-140. [PubMed: 15862213]

Sun SW, Liang HF, Le TQ, Armstrong RC, Cross AH, Song SK. Differential sensitivity of in vivo and ex vivo diffusion tensor imaging to evolving optic nerve injury in mice with retinal ischemia. Neuroimage. 2006; 32(3):1195-1204. [PubMed: 16797189]

Szeszko PR, Robinson DG, Ashtari M, Vogel J, Betensky J, Sevy S, et al. Clinical and neuropsychological correlates of white matter abnormalities in recent onset schizophrenia. Neuropsychopharmacology. 2008; 33(5):976-984. [PubMed: 17581532]

Tkachev D, Mimmack ML, Huffaker SJ, Ryan M, Bahn S. Further evidence for altered myelin biosynthesis and glutamatergic dysfunction in schizophrenia. Int J Neuropsychopharmacol. 2007; 10(4):557-563. [PubMed: 17291371] 
Uranova NA, Orlovskaia DD, Vikhreva OV, Zimina IS, Rakhmanova VI. Morphometric study of ultrastructural changes in oligodendroglial cells in the postmortem brain in endogenous psychoses. Vestn Ross Akad Med Nauk. 2001; (7):42-48. [PubMed: 11523429]

Uranova NA, Vostrikov VM, Orlovskaya DD, Rachmanova VI. Oligodendroglial density in the prefrontal cortex in schizophrenia and mood disorders: a study from the Stanley Neuropathology Consortium. Schizophrenia research. 2004; 67(2-3):269-275. [PubMed: 14984887]

Wakana S, Caprihan A, Panzenboeck MM, Fallon JH, Perry M, Gollub RL, et al. Reproducibility of quantitative tractography methods applied to cerebral white matter. Neuroimage. $2007 ; 36(3): 630$ 644. [PubMed: 17481925]

Weinberger DR, Berman KF, Suddath R, Torrey EF. Evidence of dysfunction of a prefrontal-limbic network in schizophrenia: a magnetic resonance imaging and regional cerebral blood flow study of discordant monozygotic twins. The American journal of psychiatry. 1992; 149(7):890-897. [PubMed: 1609867]

Wernicke, C. Grundrisse der psychiatrie. Thieme; Leipzig: 1906.

White T, Schmidt M, Karatekin C. White matter 'potholes' in early-onset schizophrenia: a new approach to evaluate white matter microstructure using diffusion tensor imaging. Psychiatry Res. 2009; 174(2):110-115. [PubMed: 19853414]

Wible CG, Anderson J, Shenton ME, Kricun A, Hirayasu Y, Tanaka S, et al. Prefrontal cortex, negative symptoms, and schizophrenia: an MRI study. Psychiatry Res. 2001; 108(2):65-78. [PubMed: 11738541]

Wilkinson, GS.; Robertson, GJ. Wide Range Achievement Test 4 professional manual. Psychological Assessment Resources; Lutz, FL: 2006.

Wolkin A, Choi SJ, Szilagyi S, Sanfilipo M, Rotrosen JP, Lim KO. Inferior frontal white matter anisotropy and negative symptoms of schizophrenia: a diffusion tensor imaging study. The American journal of psychiatry. 2003; 160(3):572-574. [PubMed: 12611842]

Woods SW. Chlorpromazine equivalent doses for the newer atypical antipsychotics. The Journal of clinical psychiatry. 2003; 64(6):663-667. [PubMed: 12823080] 


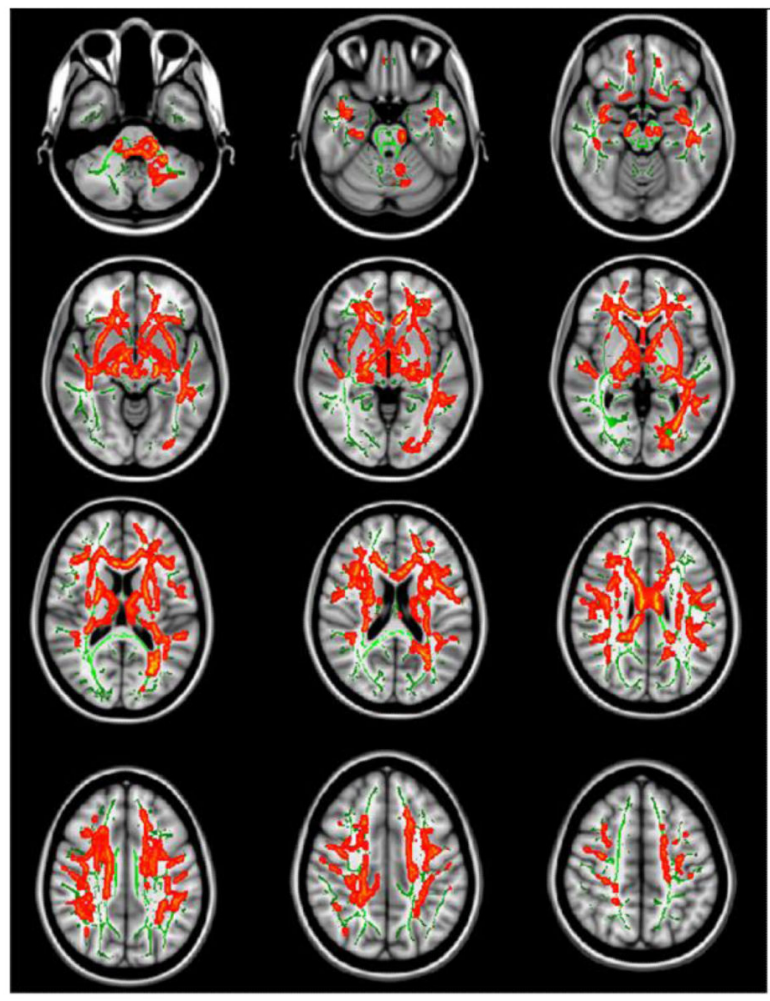

Figure 1.

Regions of significant FA reduction in first episode schizophrenia $(\mathrm{N}=17)$ compared to normal (controls $\mathrm{N}=17$ ). Red-Yellow indicates $\mathrm{p}$ value ( $\mathrm{p}<0.05, \mathrm{p}<0.01$ respectively).

Results are shown overlaid on the Montreal Neurologic Institute $1 \mathrm{~mm}$ template $(\mathrm{Z}=-37$ to $\mathrm{Z}=47$ ) and the mean FA skeleton (green). Permutation-based inference tool for nonparametric statistics, Threshold-free cluster enhancement method was used. Number of permutation was 5000. FWE was corrected $\mathrm{p}<0.05$. Left-right orientation is according to the radiological convention. 


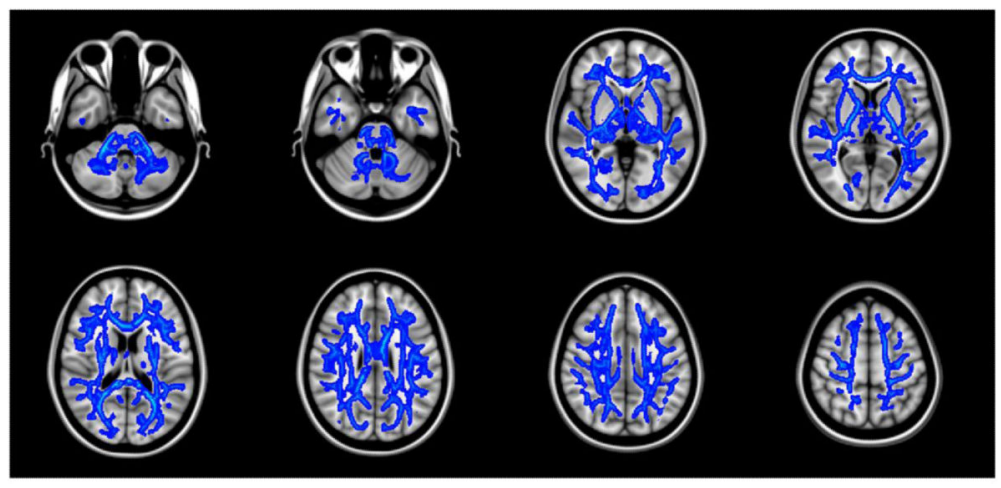

Figure 2.

Almost all the white matter showed significant increase of the trace value in first-episode schizophrenia compared to normal controls. Blue-Lightblue indicates $p$ value $(p<0.05$, $\mathrm{p}<0.01$ respectively). Results are shown overlaid on the Montreal Neurologic Institute $1 \mathrm{~mm}$ template $(\mathrm{Z}=-36$ to $\mathrm{Z}=52)$. 


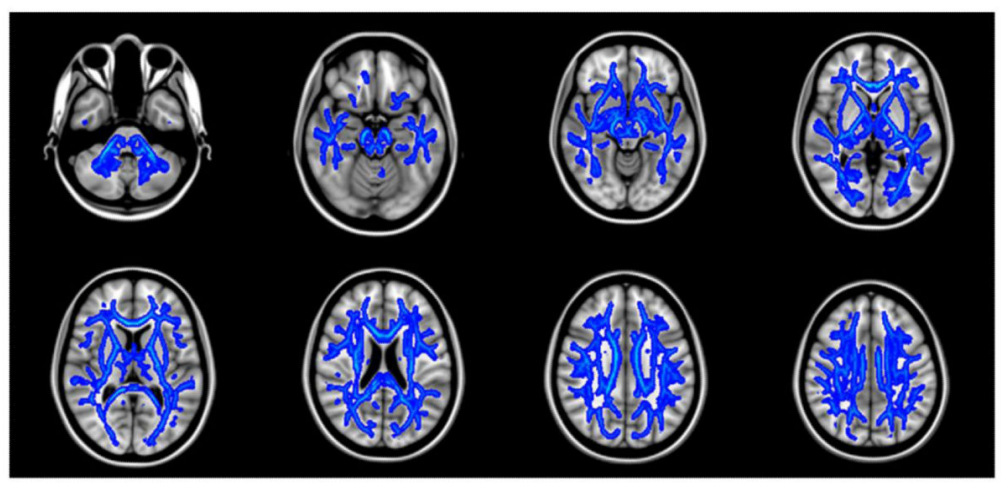

Figure 3.

The radial diffusivity of first episode schizophrenia also showed almost all the white matter abnormality compared to normal controls. Blue-Lightblue indicates $p$ value $(p<0.05, p<0.01$ respectively). Results are shown overlaid on the Montreal Neurologic Institute $1 \mathrm{~mm}$ template $(\mathrm{Z}=-37$ to $\mathrm{Z}=35)$. 

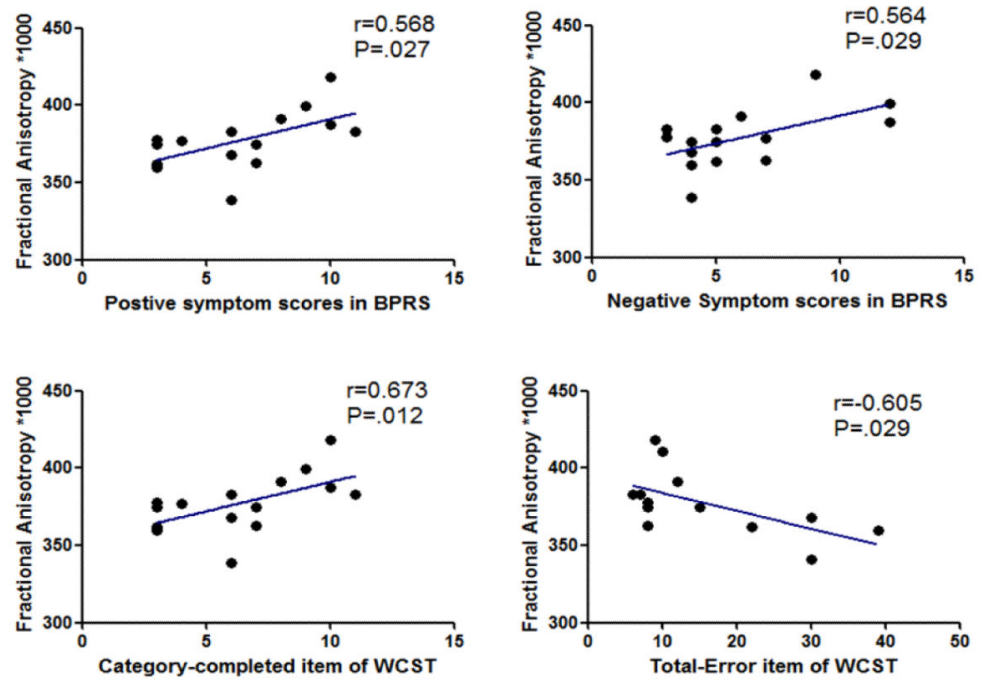

Figure 4.

Correlation analysis in the mean FA values of the right fronto-occipital fasciculus. BPRS, Brief Psychiatric Rating Scale; WCST, Wisconsin Card Sorting Test. 
Table 1

Comparison of the demographic characteristics for first-episode schizophrenia and healthy control

\begin{tabular}{|c|c|c|c|c|c|}
\hline & $\begin{array}{c}\text { FESZ } \\
\substack{(\mathrm{Mean} \pm \mathrm{SD}) \\
(\mathbf{n}=17)}\end{array}$ & $\underset{(\mathbf{M e a n} \pm \mathbf{S D})}{\mathbf{H C}}$ & $\mathbf{t}$ & df & $p$ \\
\hline Age at scan(years) & $21.5 \pm 4.8$ & $23.1 \pm 3.5$ & -1.11 & 32 & 0.27 \\
\hline Gender(Male/Female) & $13 / 4$ & $12 / 5$ & & & $1.00^{a}$ \\
\hline Education(years) & $13.7 \pm 3.1$ & $14.1 \pm 1.7$ & -0.50 & 23.7 & 0.62 \\
\hline Parental SES & $2.3 \pm 1.5$ & $1.7 \pm 0.7$ & 1.25 & 20.3 & 0.23 \\
\hline $\begin{array}{l}\text { Current estimated } \\
\text { Iintellectual ability }\end{array}$ & $114.1 \pm 11.7$ & $118.9 \pm 10.4$ & -1.1 & 25 & 0.27 \\
\hline Ethnicity $(\mathrm{H} / \mathrm{N} / \mathrm{U})^{b}$ & $4 / 13 / 0$ & $1 / 15 / 1$ & & & \\
\hline $\begin{array}{l}\text { Asian East } \\
\text { Southwest }\end{array}$ & 1 & & & & \\
\hline Asian, Western & & 9 & & & \\
\hline $\begin{array}{l}\text { Black or African } \\
\text { American }\end{array}$ & 1 & 4 & & & \\
\hline White & 14 & 3 & & & \\
\hline Other & 1 & 16 & & & \\
\hline 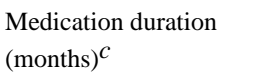 & $4.56 \pm 3.10$ & & & & \\
\hline Medication dose $(\mathrm{mg})^{d}$ & $393.3 \pm 358.2$ & & & & \\
\hline $\begin{array}{l}\text { WCST }{ }^{e} \text { categories } \\
\text { completed }\end{array}$ & $3.2 \pm 1.7$ & $5.4 \pm 1.4$ & -3.4 & 23 & 0.02 \\
\hline
\end{tabular}

FESZ, first-episode schizophrenia; HC, healthy control; SES; socioeconomic status. Current iIntellectual ability was estimated with 2 subtests from the measured by WASI or WAIS-III IQ

${ }^{a}$ Fisher's exact test.

${ }^{b}$ Ethnicity: H=Hispanic or Latino; N=Not Hispanic or Latino; U=Unknown

${ }^{c}$ Antipsychotic medication duration of all patients

${ }^{d}$ Antipsychotic medication dose of all patients equivalent to chloropromazine at the time of scan.

$e_{\text {WCST: the Wisconsin Card Sorting Test }}$ 
Table 2

Comparison of the fractional anisotropy between first-episode schizophrenia and healthy control using atlasbased segmentation

\begin{tabular}{|c|c|c|c|c|c|}
\hline & $\begin{array}{c}\text { FESZ } \\
(\text { Mean } \pm \text { SD })\end{array}$ & $\begin{array}{c}\mathrm{NC} \\
(\mathrm{Mean} \pm \mathrm{SD})\end{array}$ & $\mathbf{t}$ & df & $\mathbf{p}$ \\
\hline Genu of corpus callosum & $0.141 \pm 0.007$ & $0.148 \pm 0.012$ & -2.12 & 32 & $0.04^{*}$ \\
\hline $\begin{array}{l}\text { Splenium of corpus } \\
\text { callosum }\end{array}$ & $0.270 . \pm 0.012$ & $0.282 \pm 0.019$ & -3.08 & 32 & $0.004^{* *}$ \\
\hline $\begin{array}{l}\text { Posterior limb of internal } \\
\text { capsule, left }\end{array}$ & $0.416 \pm 0.014$ & $0.427 \pm 0.016$ & -2.25 & 32 & $0.032^{*}$ \\
\hline Fornix/Stria terminalis, right & $0.225 \pm 0.009$ & $0.238 \pm 0.014$ & -3.31 & 32 & $0.002^{* *}$ \\
\hline Fornix/Stria terminalis, left & $0.217 \pm 0.009$ & $0.232 \pm 0.012$ & -3.39 & 32 & $<0.0011^{* * *}$ \\
\hline $\begin{array}{l}\text { Superior frontooccipital } \\
\text { fasciculus, right }\end{array}$ & $0.241 \pm 0.024$ & $0.258 \pm 0.025$ & -2.13 & 32 & $0.04^{*}$ \\
\hline $\begin{array}{l}\text { Inferior frontooccipital } \\
\text { fasciculus, left }\end{array}$ & $0.196 \pm 0.010$ & $0.205 \pm 0.011$ & -2.58 & 32 & $0.01^{*}$ \\
\hline $\begin{array}{l}\text { Cingulum(hippocampus) } \\
\text { right }\end{array}$ & $0.222 \pm 0.011$ & $0.232 \pm 0.011$ & -2.42 & 32 & $0.022^{*}$ \\
\hline Cingulum(hippocampus) left & $0.216 \pm 0.010$ & $0.227 \pm 0.011$ & -3.02 & 32 & $0.005^{* *}$ \\
\hline Uncinate fasciculus, right & $0.162 \pm 0.016$ & $0.185 \pm 0.013$ & -2.57 & 32 & $0.01^{*}$ \\
\hline Uncinate fasciculus, left & $0.169 \pm 0.017$ & $0.187 \pm 0.025$ & -2.07 & 32 & $0.04^{*}$ \\
\hline
\end{tabular}

FESZ, first-episode schizophrenia; HC, healthy control.

$* 0.05$

$* *<0.01$

$* * *<0.001$ by independent $t$ test. 